\title{
Effect of Sea Surface Temperature Errors on Snowfall in WRF: A Case Study of a Heavy Snowfall Event in Korea in December 2012
}

\author{
Jaein I. Jeong, Rokjin J. Park ${ }^{*}$, and Yang-Ki Cho \\ School of Earth and Environmental Sciences, Seoul National University, Seoul, Korea
}

Received 6 December 2013, revised 14 August 2014, accepted 15 August 2014

\begin{abstract}
We examined the sensitivity of simulated snowfall to prescribed sea surface temperature (SST) data using the Weather Research and Forecasting (WRF) model and the Operational Sea Surface Temperature and Sea Ice Analysis (OSTIA) SST dataset for the Korean Peninsula. The OSTIA data were initially compared with in situ buoy measurements from three coastal sites in the Yellow Sea and was shown to be in good agreement with the in situ data with root mean square errors of $0.14-0.17 \mathrm{~K}$ for the daily mean values. Next, we conducted several WRF simulations, including a baseline simulation with the OSTIA data and sensitivity simulations with a temporally and spatially varying SST. The simulations were run for the Yellow Sea during December 2012 when a severe snowfall occurred in Korea. The baseline model generally captured the observed spatial and temporal variations of snowfall, surface air temperature and surface pressure in Korea. The sensitivity simulations with an increased and decreased SST resulted in a variation of $+0.8 /-0.7 \mathrm{~K}$ for the surface air temperature, $\pm 0.6 \mathrm{hPa}$ for the surface pressure, and $\pm 0.3 \mathrm{~m} \mathrm{~s}^{-1}$ for the surface wind speed, in relation to the baseline simulation. The SST deviation affected the precipitation variability with changes of $\pm 9 \%$ for snowfall and $\pm 18 \%$ for rainfall, indicating considerable model sensitivity to SST perturbations. The change in the meteorological variables of the upper layer induced by the SST perturbations showed a symmetrical structure with respect to warmer and colder SST. Nevertheless, ice represented a nonlinear combination of the results at the low and mid-levels.
\end{abstract}

Key words: Sea surface temperature, Snowfall, WRF, Yellow Sea, OSTIA

Citation: Jeong, J. I., R. J. Park, and Y. K. Cho, 2014: Effect of sea surface temperature errors on snowfall in WRF: A case study of a heavy snowfall event in Korea in December 2012. Terr. Atmos. Ocean. Sci., 25, 827-837, doi: 10.3319/TAO.2014.08.15.01(A)

\section{INTRODUCTION}

Sea surface temperature (SST) plays an important role in synoptic weather systems by determining the exchange of moisture, heat and momentum between the atmosphere and the ocean surface. Therefore, SST data should be provided as a boundary condition for weather forecasting systems (Donlon et al. 2012). Near real time SST datasets are produced by the Group for High Resolution SST (GHRSST) using available satellite and in situ observations (Martin et al. 2012). Daily values are typically on a $0.05^{\circ} \times 0.05^{\circ}$ horizontal resolution.

However, differences in measurement techniques make the accuracy of the SST values questionable, resulting in significant changes between datasets (Dash et al. 2012). A previous inter-comparison study of SST values showed that the GHRSST datasets have significant biases for both

\footnotetext{
* Corresponding author

E-mail:rjpark@snu.ac.kr
}

warm and cold temperatures, especially along the coast and the shelf sea of East Asia (Xie et al. 2008). Moreover, when used to fill gaps in one dataset by combining other datasets, the optimal interpolation method causes substantial temporal and spatial errors on SST data (Donlon et al. 2012).

Therefore, it is crucial to quantify the effect of SST uncertainty or errors on the simulation of meteorological conditions to better forecast weather systems. Park et al. (2011) showed that SST perturbations significantly affect the air temperature at the sea surface, the atmospheric stability and the vertical moisture fluxes. Jeong and Park (2013) also reported that $\pm 1.1^{\circ} \mathrm{C}$ perturbations in SST result in changes in air temperature of $+0.37 /-0.38^{\circ} \mathrm{C}$, and in surface pressure of $\pm 0.31 \mathrm{hPa}$ over the Yellow Sea. Cha et al. (2011) showed that SST deviations affect cloud streets and snowfall formation. These studies examined the sensitivity of simulations with respect to uniform SST deviations by increasing 
or decreasing SST values throughout the model domain for the simulation period. However, errors in SST data are both space and time dependent.

In this study, we first quantified the spatial and temporal errors of the Operational Sea Surface Temperature and Sea Ice Analysis (OSTIA) SST dataset by comparison with in situ buoy observations for the Yellow Sea. Next, we examined the sensitivity of model simulations to the estimated SST errors, primarily focusing on a heavy snowfall event that occurred in December 2012. The analysis of our results will provide suggestions to improve weather forecasting systems associated with SST data.

\section{SST DATA AND MODEL DESCRIPTION}

In this study, we used the recently developed OSTIA SST dataset, which is known to provide realistic values for East Asia (Xie et al. 2008). The OSTIA data are widely used in global and regional meteorological simulations, but biases of $1.5-2 \mathrm{~K}$ have been observed, especially for coastal regions, owing to the coarse spatial resolution of the satellite measurements (Xie et al. 2008; Donlon et al. 2012). Xie et al. (2008) previously compared five SST datasets with in situ observations over the East Asian Sea and found that the OSTIA SST was significantly closer to the in situ observations. The OSTIA data are produced using in situ and satellite observations provided by international agencies via the GHRSST. Values have a nearly global coverage on a daily scale with a horizontal resolution of $0.05^{\circ} \times 0.05^{\circ}$ (Stark et al. 2007; Donlon et al. 2012). The data are bias-corrected based on a combination of Environmental Satellite Advanced Along Track Scanning Radiometer SST data and in situ measurements from drifting buoys (Donlon et al. 2012).

Figure 1a shows the spatial distribution of the monthly mean OSTIA SST data around the Korean Peninsula in December 2012. The values show a large meridional gradient over the Yellow Sea. Figure 1b shows the monthly mean OSTIA SST errors calculated through a multiscale optimal interpolation that uses all available GHRSST datasets and in situ observations (Reynolds et al. 2007). These include sampling, random and bias errors and are required by the OSTIA data assimilation systems. The domain-averaged SST error was $1.4 \mathrm{~K}$, with higher values occurring in coastal seas typically within $100 \mathrm{~km}$ from the shore. Because of cloud interference in these areas, the satellite observations are too limited to capture the high temporal and fine spatial variability of SST (Donlon et al. 2012).

We used the Weather Research and Forecasting model (WRF-ARW, Advanced Research WRF) (version 3.4.1) to examine the effect of SST errors on the simulation of atmospheric variables around the Korean Peninsula. The model is fully compressible and non-hydrostatic and uses the massbased terrain following coordinate system on the Arakawa$\mathrm{C}$ grid. The second and third order Runge-Kutta time integration technique was used for model integration. The WRF model conserves mass, momentum, entropy and scalars using flux form prognostic equations. The physics packages include the WRF double-moment 6-class (WDM6) microphysics scheme (Lim and Hong 2010), the Kain-Fritsch cumulus parameterization scheme (Kain 2004), the Noah land-surface model (Chen and Dudhia 2001), the Yonsei University planetary boundary layer (PBL) (Hong et al. 2006), the longwave radiation schemes from the Rapid Radiative Transfer Model (RRTM) (Mlawer et al. 1997), and a simple cloud-interactive radiation scheme (Dudhia 1989). The WDM6 simulates six water species: water vapor, cloud droplets, cloud ice, snow, rain, and graupel. The sub-grid cumulus parameterization was only used for simulations with horizontal resolutions of 27 and $9 \mathrm{~km}$ since no cumulus scheme is generally needed for simulations with horizontal resolutions of $3 \mathrm{~km}$ or less (Hong and Dudhia 2012).

We used two-way nested domains, allowing for the interaction between outer and inner domains. The outer domain was integrated first and the boundary conditions for the inner domain were obtained from the predictions for the outer domain. The solutions for the inner domain were
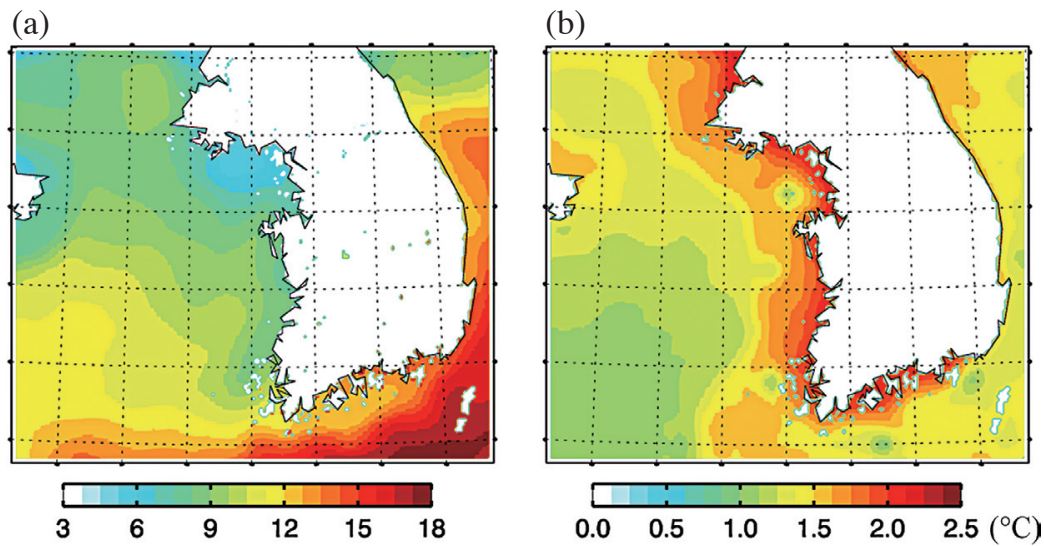

Fig. 1. Monthly mean distribution of (a) OSTIA SST and (b) OSTIA SST error values around the Korean Peninsula. 
averaged back to the outer domain, replacing the solution for the outer domain over the overlapped regions (Skamarock et al. 2005; Moeng et al. 2007). The largest domain consisted of a $100 \times 100$ horizontal grid, with a $27-\mathrm{km}$ resolution over East Asia (Fig. 2). The two nested domains had $181 \times 160$ and $253 \times 223$ horizontal grid points, with 9 - and $3-\mathrm{km}$ resolutions, respectively.

The model has 27 vertical layers with the top at $50 \mathrm{hPa}$. For the initial and boundary conditions we used the 6-h operational global analysis data from the National Centers for Environmental Prediction Final (NCEP FNL) with a $1^{\circ} \times 1^{\circ}$ resolution. We conducted WRF simulations for 33 days with the first $48 \mathrm{~h}$ being considered as spin-up time. The atmospheric fields within domain 3 were analyzed from 0000 UTC 1 December 2012 to 0000 UTC 1 January 2013. Our analysis primarily focused on the results from the innermost nested domain since the 27- and 9-km resolution simulations were too coarse to resolve the fine-scale variation in precipitation. In addition, previous studies suggested that a horizontal resolution greater than $3 \mathrm{~km}$ is not fine enough to simulate cloud streets and heavy snowfall (Lee 2002; Kang and Ahn 2008).

To investigate the effect of SST errors on the meteorological fields, three sets of numerical simulations, a control (CTL) and two sensitivity runs, were carried out. The CTL simulation used the OSTIA SST data (Donlon et al. 2012) while the two sensitivity simulations used the OSTIA SST after increasing (WSST; relatively warm SST) or decreasing (CSST; relatively cold SST) the SST values according to the time-varying, inhomogeneous SST errors for each grid point. The results from the CTL run were used for model evaluation. The results from the sensitivity simulations were analyzed to examine the effect of SST errors on the meteorological variables over the Yellow Sea and Korean Peninsula. All simulations were conducted using the same initial and boundary conditions except for the SST data.

\section{MODEL EVALUATION FOR THE HEAVY SNOWFALL EVENT OF DECEMBER 2012}

During the winter season of 2012, intense snowfall generally occurs in the western part of the Korean Peninsula, especially in Chungcheong and Jeolla provinces (Fig. 2). Cheong et al. (2006) suggested that the mechanisms of heavy snowfall over the western part of the Korean Peninsula are related to the transformation of the air mass accompanied by heat and moisture supply, when the Siberian High passes over the Yellow Sea.

Figure 3 shows the surface weather chart for 0000 UTC 22 December and 0000 UTC 23 December 2012 when a heavy snowfall occurred in the Korean Peninsula. On 22 December, a well-developed Siberian High was located in Mongolia, with the Korean Peninsula also influenced by a cold air mass. On 23 December, the Siberian High extended eastward and the isobars tilted perpendicularly over the
Yellow Sea. As this continental cold air mass moved over the Korean Peninsula it was rapidly modified by the heat and moisture fluxes originating from the warm Yellow Sea, leading to an increase in instability. On 23 December, the isotherms and isobars at $850 \mathrm{hPa}$ over the Yellow Sea were almost perpendicular to each other, suggesting an intensification of the baroclinicity in that area. A synoptic scale deep trough at $500 \mathrm{hPa}$ was located over the Yellow Sea with a cold low in Manchuria, providing a favorable synoptic condition for the formation of a meso-cyclone.

The accuracy of the OSTIA SST dataset was assessed by comparison with the in situ buoy observations from the Korea Meteorological Administration (KMA). These buoys are located in the Yellow Sea, approximately $50 \mathrm{~km}$ offshore the west coast of the Korean Peninsula (Fig. 2). Figure 4 shows the daily mean SST for Deokjeokdo $\left(37.2^{\circ} \mathrm{N}, 126.1^{\circ} \mathrm{E}\right)$, Oeyeondo $\left(36.3^{\circ} \mathrm{N}, 125.8^{\circ} \mathrm{E}\right)$, and Chilbaldo $\left(34.8^{\circ} \mathrm{N}, 125.8^{\circ} \mathrm{E}\right)$ from the in situ measurements and the OSTIA datasets. The in situ data showed a gradual decrease towards the end of the month. The OSTIA SST was in good agreement with the in situ measurements, with low root mean square errors (RMSE) of 0.14, 0.27, and 0.23 K for Deokjeokdo, Oeyeondo, and Chilbaldo, respectively. Compared to the typical RMSE $(0.89 \mathrm{~K})$ of satellite retrieved SST over East Asia (Park et al. 2008), the OSTIA data appear to represent well the temporal and spatial variability of SST over the Yellow Sea.

Figure 5 compares the observed and simulated snowfall for December 2012 over the Korean Peninsula. The observed monthly snowfall from the KMA showed that the southwestern coast of the Korean Peninsula, especially the Chungcheong and North Jeolla provinces, received more than $20 \mathrm{~cm}$ of snow, with a maximum of $58.7 \mathrm{~cm}$ in Gochang, in December 2012. The spatial distribution of the simulated snowfall was similar to the observed, although with an underestimation for the southern coastal areas. Figure 5 also compares the observed and simulated surface air temperature and surface pressure, which were highly influenced by SST deviations. The observed surface air temperature was higher in the southern and eastern coastal areas of the Korean Peninsula. The simulated surface air temperature showed a similar spatial pattern, especially for the eastern coastal area, as a result of the high SST in the East/Japan Sea (Fig. 1a). The spatial patterns of the observed and simulated surface pressures matched well with the high pressure in the coastal area and the low pressure in the continent due to the topographic effect. A site-by-site snowfall comparison showed a relatively a poor correlation coefficient $(R=0.65)$ between the model and the observations, whereas the model reproduced well the observed spatial variability with high $R$ values for the surface air temperature $(R=0.96)$ and the surface pressure $(\mathrm{R}=0.92)$ in Korea.

Figure 6 compares the observed and simulated daily snowfall averaged for 12 KMA stations over the Chungcheong and Jeolla provinces. The model captured the 
observed temporal variation of snowfall in early and late December 2012, when two heavy snowfall events occurred on the Korean peninsula. Although the model slightly underestimated the snowfall in late December, the results indicate that the model generally reproduced the observed snowfall with high $R$ values $(R=0.86)$ over the Chungcheong and Jeolla provinces.

\section{SIMULATED SENSITIVITY OF SNOWFALLS TO SST VARIATION}

In this section we analyze the results from the sensitivity simulations to examine the effect of the SST errors on the meteorological fields and their implications for winter weather prediction in Korea. As discussed earlier, increased and decreased OSTIA data were used in the sensitivity simulations for the WSST and CSST cases, respectively.

Figure 7 shows the spatial distribution of the simulated meteorological fields in surface air from the CTL, WSST, and CSST runs for December 2012. Figures 7a and b show the simulated monthly mean surface air temperature and heat flux. Changes in the SST data result in changes in the surface air temperature by affecting the heat flux and thermal properties of the lower atmosphere. The spatial patterns of the simulated ocean surface air temperature and heat flux were similar to that of the OSTIA SST (Fig. 1a), reflecting the dominant role of SST as a heat source.

The effect of SST errors on the surface air temperature and heat flux is also shown in Figs. $7 \mathrm{a}$ and b. The results indicate that the temperature impact was higher on the ocean than on land and shows an increase and decrease in air

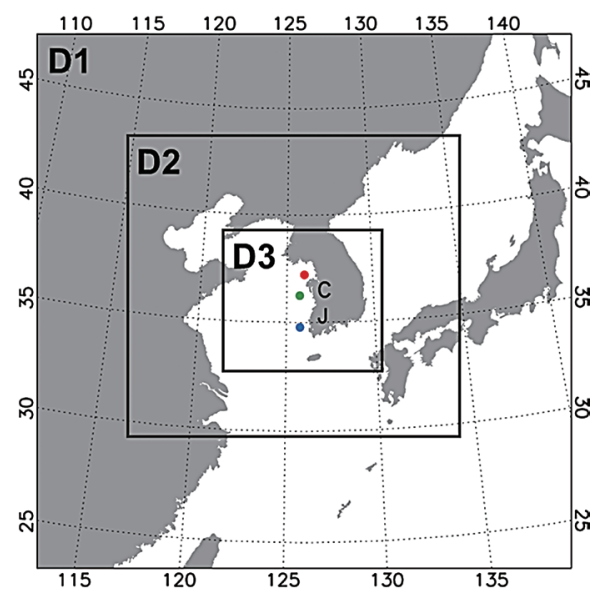

Fig. 2. Model domain for the $27-\mathrm{km}$ resolution $100 \times 100$ grid (D1), the $9-\mathrm{km}$ resolution $181 \times 160$ grid (D2), and the $3-\mathrm{km}$ resolution $253 \times 223$ grid (D3). The buoy sites at Deokjeokdo, Oeyeondo, and Chilbaldo over the Yellow Sea are represented by red, green and blue circles, respectively. "C" and "J" represent the Chungcheong and Jeolla provinces, respectively. (a)

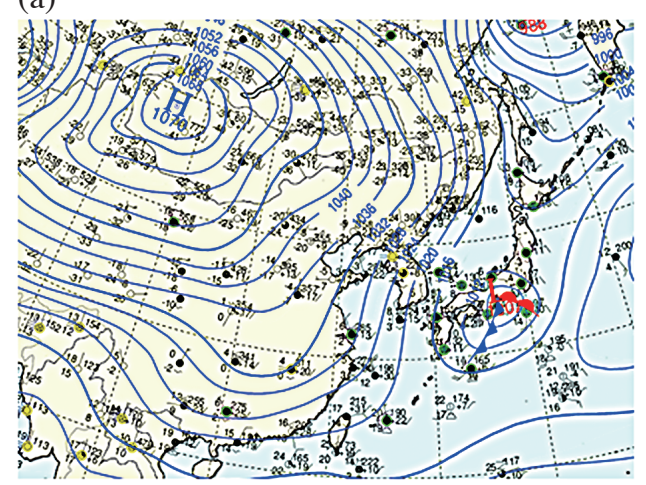

(c)

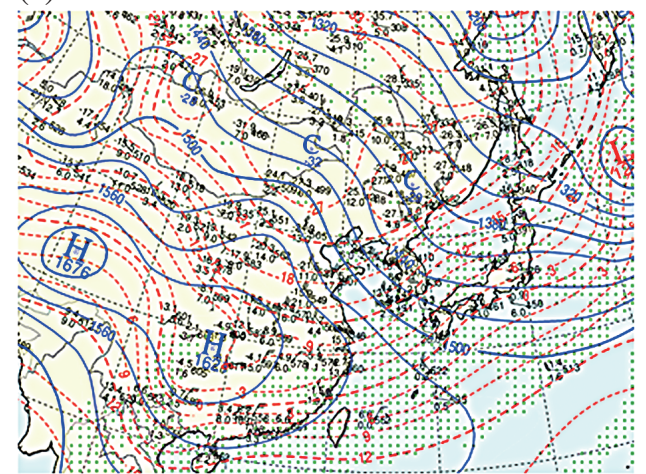

(b)

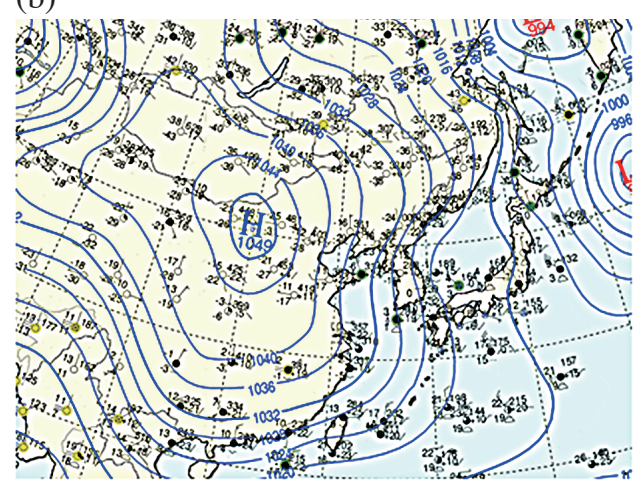

(d)

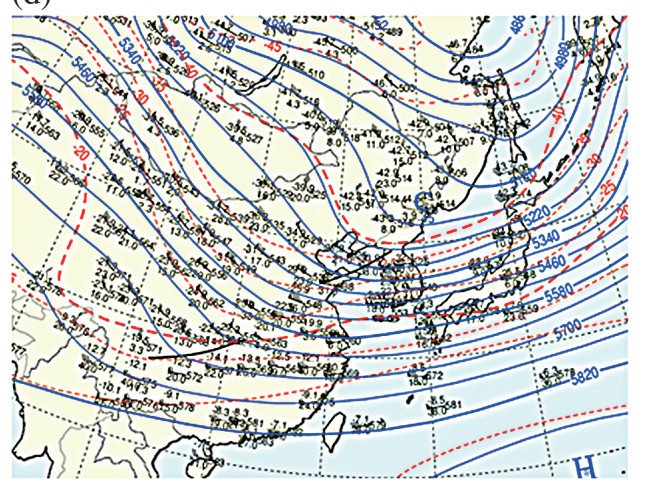

Fig. 3. Surface weather charts at (a) 0000 UTC 22 December 2012 and (b) 0000 UTC 23 December 2012. Upper level weather charts at (c) 850 hPa and (d) $500 \mathrm{hPa}$ at 0000 UTC 23 December 2012. 


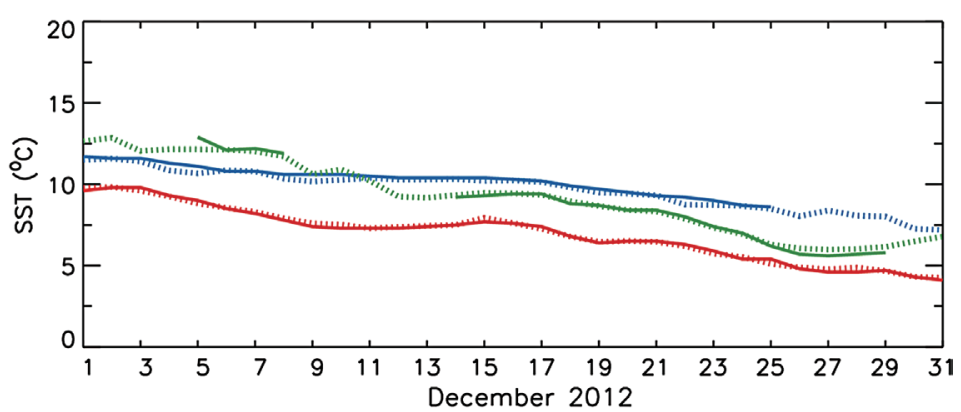

Fig. 4. Time series of in situ buoy (solid line) and OSTIA (dotted line) SST at Deokjeokdo (red), Oeyeondo (green), and Chilbaldo (blue) over the Yellow Sea in December 2012. The OSTIA SST data are the grid point values corresponding to the buoy sites.

(a)

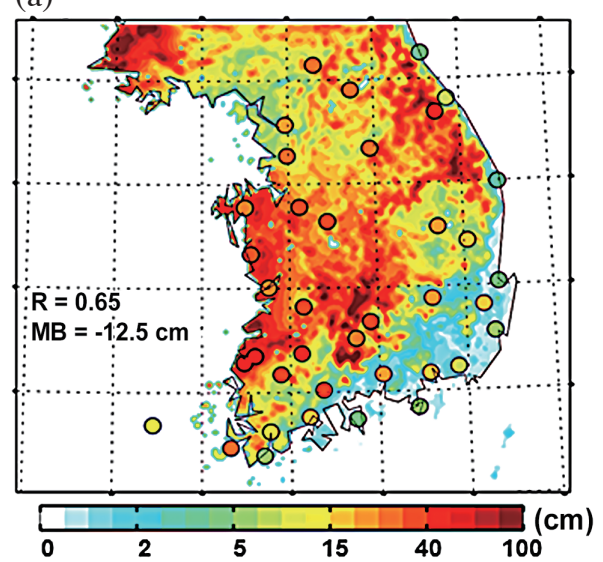

(c)

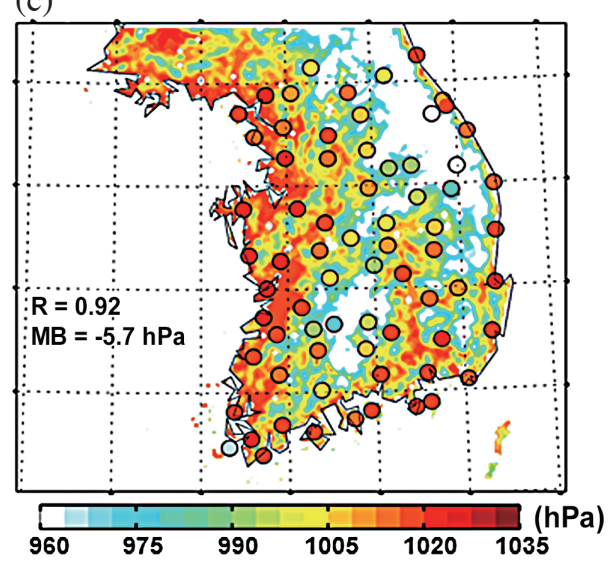

(b)

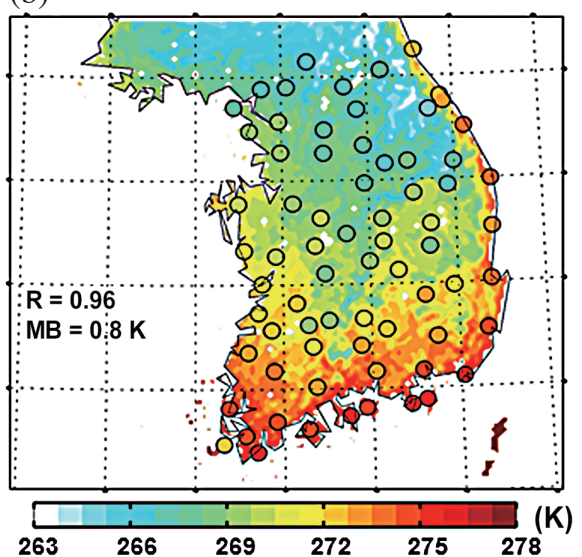

Fig. 5. Spatial distribution of simulated (a) accumulated snowfields, (b) surface air temperature, and (c) surface pressure in December 2012. The closed circles represent the observed data obtained by the KMA. Spatial correlation coefficient $(R)$ and mean bias $(M B=\bar{M}-\bar{O}$, where $M$ and $O$ are the modeled and observed values, respectively) are given as an inset.

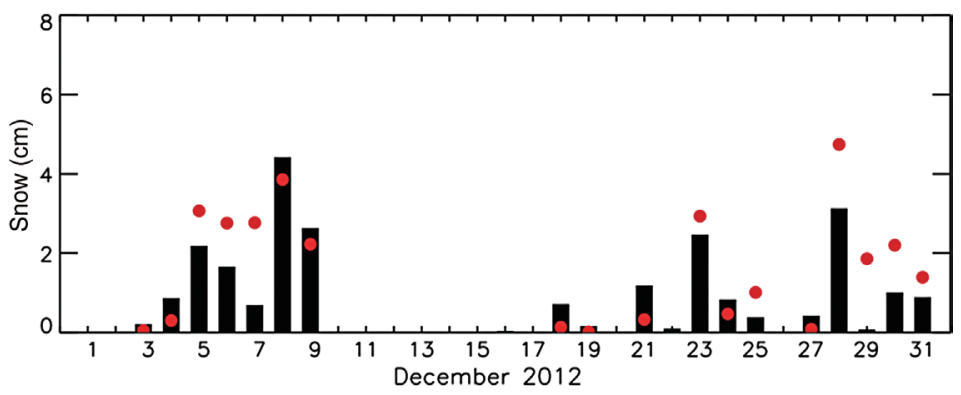

Fig. 6. Time series plot of the observed (red circles) and simulated (black bars) daily snow volumes ( $\mathrm{cm}$ ) averaged for 12 sites over the Chungcheong and Jeolla provinces in December 2012. 

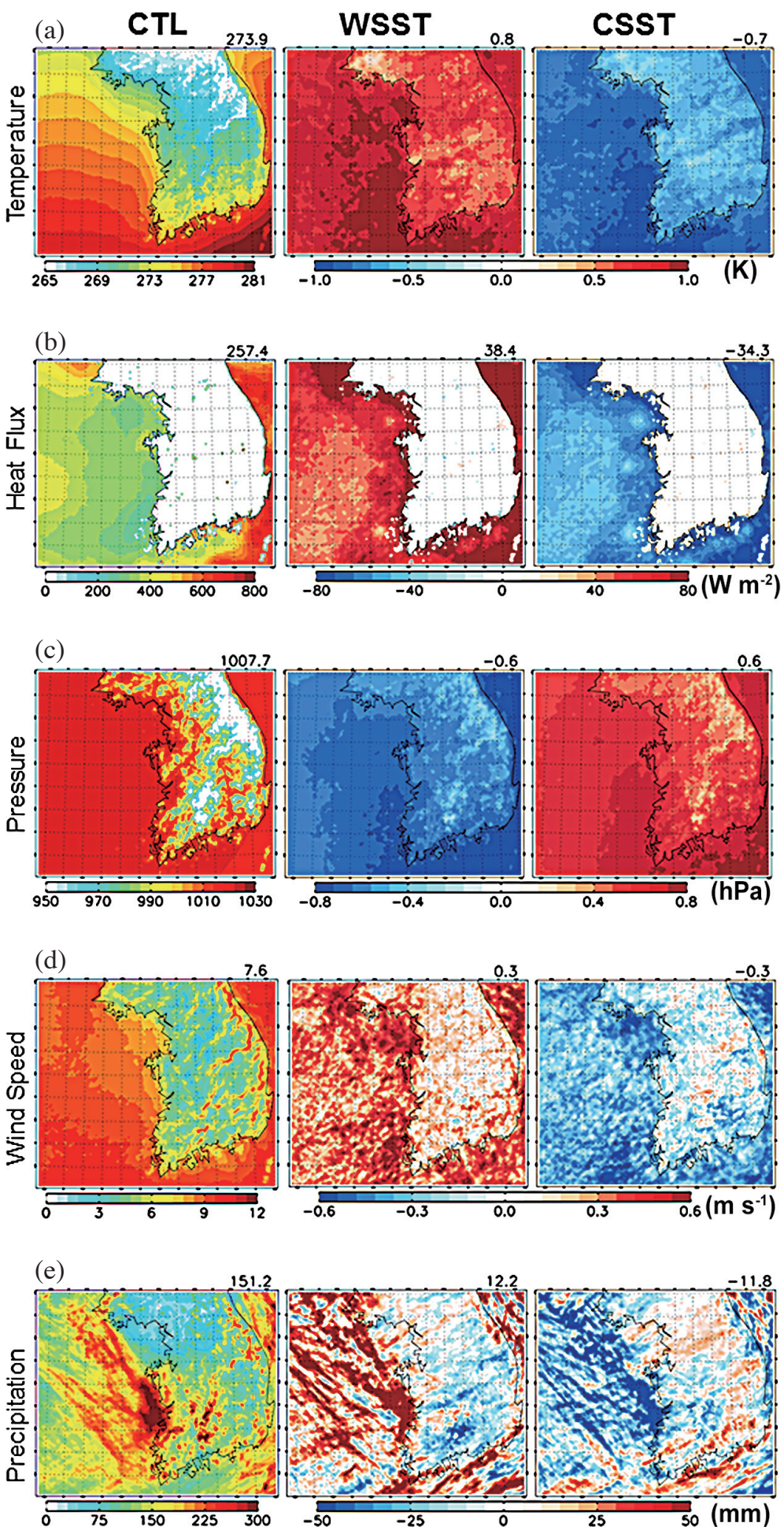

Fig. 7. Horizontal distribution of the CTL and the anomalies of WSST and CSST relative to the CTL in (a) surface air temperature, (b) sensible and latent heat flux, (c) surface pressure, (d) surface wind speed, and (e) precipitation in December 2012. The domain-averaged values are shown in the upper right corner for each panel.

temperature of $+0.8 /-0.7 \mathrm{~K}$ and up to $\pm 1.3 \mathrm{~K}$ for the WSST and CSST cases, respectively. The averaged sensible and latent heat fluxes in the surface air showed similar patterns, so we will only discuss the total (sensible + latent) heat flux in this study. The anomaly distributions in the heat flux for the WSST and CSST cases were similar to those for the OSTIA SST errors (Fig. 1b), implying that changes in SST data directly control the heat fluxes between the atmosphere 
and the ocean in the range of $+38 /-34 \mathrm{~W} \mathrm{~m}^{-2}$ for the WSST and CSST cases, respectively.

SST variability perturbs the surface heat fluxes, which in turn modify the pressure gradient in the marine boundary layer and the vertical turbulent fields (O'Neill et al. 2012). The thermally induced pressure gradient is formed in the marine boundary layer with lower (or higher) pressure and stronger (or weaker) wind speeds over relatively warm (or cold) SSTs (Cronin et al. 2003; Small et al. 2003). The pressure and wind speed anomalies showed a decrease of $0.6 \mathrm{hPa}$ and an increase of $0.3 \mathrm{~m} \mathrm{~s}^{-1}$ for the WSST case, and an increase of $0.6 \mathrm{hPa}$ and a decrease of $0.3 \mathrm{~m} \mathrm{~s}^{-1}$ for the CSST case, respectively (Figs. 7c and d).

For the CTL case, strong precipitation occurred in the west coast of Korea, reflecting the direct impact of the airsea interaction between cold air outbreaks and the relatively warm Yellow Sea, while the spatial distribution showed structures similar to the cloud streets (Fig. 7e). Compared with the CTL case in December 2012 over the Yellow Sea, the precipitation anomalies were approximately $\pm 8 \%$ for the domain average and up to $\pm 60 \mathrm{~mm} \mathrm{month}^{-1}$. Over land, the precipitation anomalies were relatively small, with the exception of the mountain area where large values resulted from topographic effects.

To examine the time-varying SST errors on the surface meteorological fields, time series of the area-averaged SST, surface air temperature, heat flux, surface pressure, rainfall and snowfall from the CTL and sensitivity runs are compared in Fig. 8. The OSTIA SST data showed a gradual decrease from 285 - $281 \mathrm{~K}$ over the Yellow Sea during December 2012 (Fig. 8a). The area-averaged OSTIA SST errors had a low temporal variability of $\sim 1.4 \mathrm{~K}$ for the entire

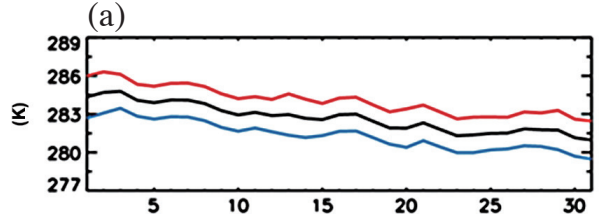

(b)

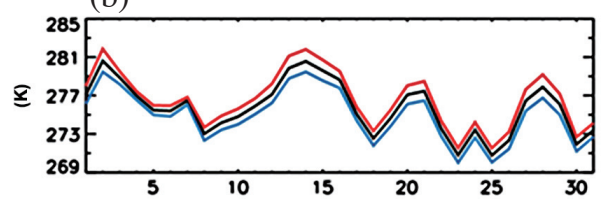

(c)

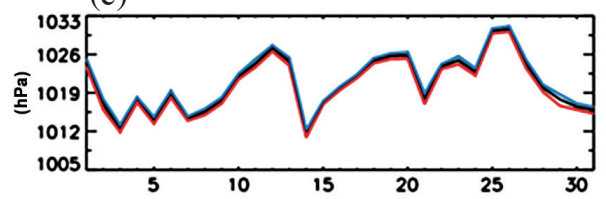

(d)

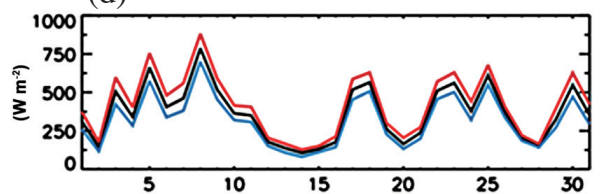

(e)

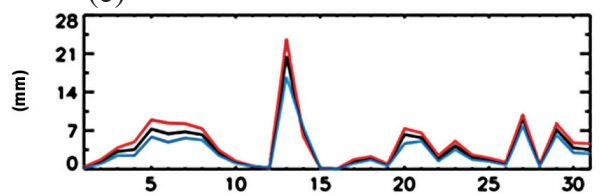

(f)

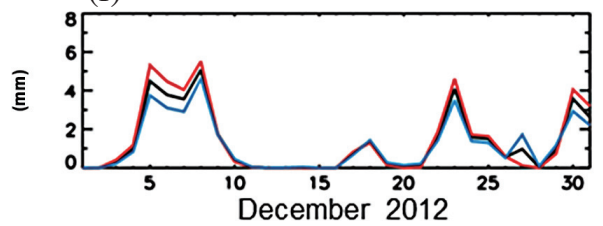

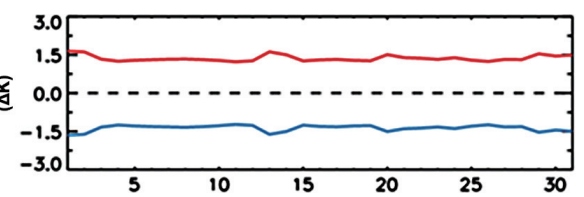
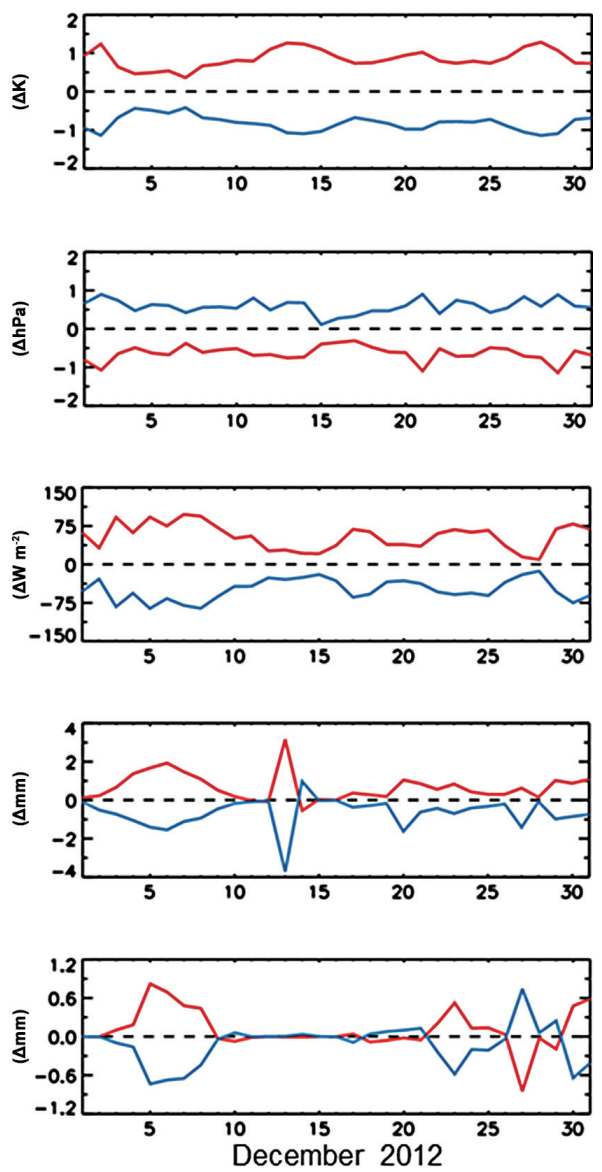

Fig. 8. Time series plot of (a) sea surface temperature, (b) surface air temperature, (c) surface pressure, (d) heat flux, (e) rainfall, and (f) snowfall for the CTL (black line), the WSST (red line), and the CSST (blue line) over the Yellow Sea $\left(34.5^{\circ}-38.5^{\circ} \mathrm{N}, 122.5^{\circ}-126.5^{\circ} \mathrm{E}\right)$ in December 2012 . The anomalies between the CTL, the WSST (red line), and the CSST (blue line) cases are shown in the right panel. 
simulation period in spite of a high spatial variability over the Yellow Sea (Fig. 1b).

The area-averaged surface air temperature showed a similar decreasing trend in December 2012 but with large fluctuations (Fig. 8b), inversely related with the surface pressure (Fig. 8c). This indicates that the surface air temperature during wintertime was highly influenced by the East Asian synoptic weather system (Ryoo et al. 2004). The sensitivity results for the surface air temperature from the WSST and CSST cases showed that large and small anomalies occurred in periods of relatively high and low surface air temperature, especially from day $13-15$ and $23-25$, respectively. This was also clear in the heat flux anomalies due to changes in SST errors (Fig. 8d). Heat flux anomalies were negatively correlated with surface air temperatures, reflecting the upward heat flux induced by the temperature difference between the atmosphere and the ocean surface.

To estimate the impact of SST errors $\left(T_{s}\right)$ on changes in surface air temperature $\left(T_{a}\right)$ and surface pressure $\left(P_{0}\right)$ in the lowest layer a transfer function was computed by dividing their anomalies by the mean SST error over the Yellow Sea. The transfer functions between $T_{a}, P_{0}$, and $T_{s}$ for the WSST and CSST cases were $0.62 / 0.60 \mathrm{~K} \mathrm{~K}^{-1}$ and $-0.47 /-0.43 \mathrm{hPa} \mathrm{K}^{-1}$, respectively. When normalizing the simulated anomalies to the changes in surface air temperature, $P_{0}$ increased, and the transfer functions for $T_{a}$ and $P_{0}$ for the WSST and CSST cases also increased to $-0.75 /-0.72 \mathrm{hPa} \mathrm{K}^{-1}$, respectively.

The rainfall and snowfall anomalies were positively correlated with the heat flux anomalies (Figs. 8e and f), indicating that the latent heat flux was strongly associated with roll type convective cells. Unlike the remaining period, on 27 December, a negative correlation was observed between the snowfall and the heat flux anomalies for all sensitivity experiments, due to the high air temperature in the surface layer (Fig. 8b). A comparison between the monthly cumulative precipitation from the baseline and sensitivity simulations over the Yellow Sea (not shown) revealed that the SST errors clearly affected the precipitation variability with changes of $\pm 9 \%$ for snowfall and $\pm 18 \%$ for rainfall, as a direct consequence of the SST perturbations.

A previous study by Park et al. (2011) showed that SST perturbations affect the stability of the boundary layer and the vertical flux of moisture. To investigate their effect on the vertical structure of the atmosphere, the anomalies for the vertical distributions over the Yellow Sea for the WSST and CSST cases are presented in Fig. 9. The positive (negative) anomalies of the air temperature near the sea surface reflected the direct effect of the relatively warm (cold) SST, with the anomaly patterns extending up to $700 \mathrm{hPa}$ (Fig. 9a). The pressure anomalies were negative (positive) at the surface

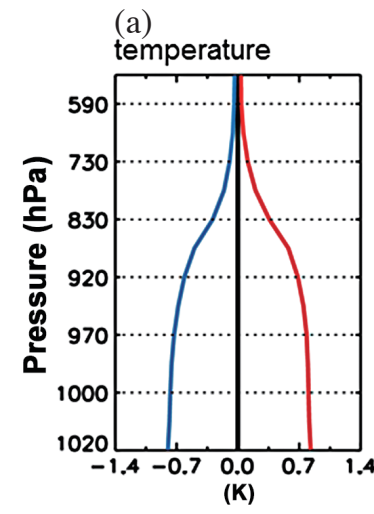

(e)

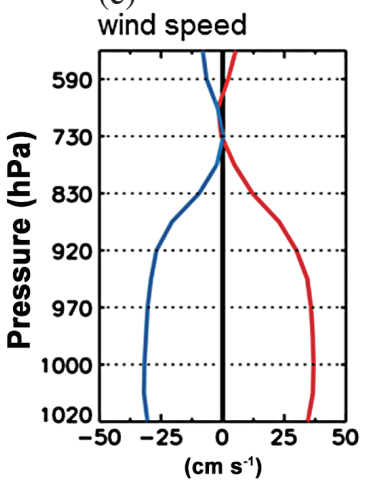

(b)

pressure

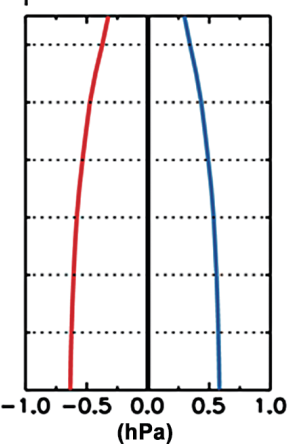

(f)

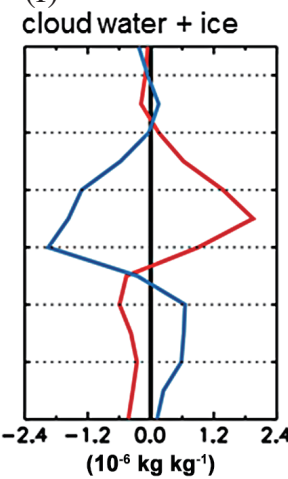

(c)

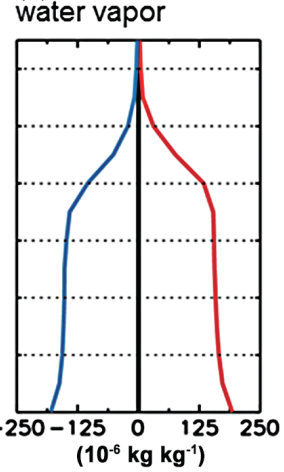

(g)

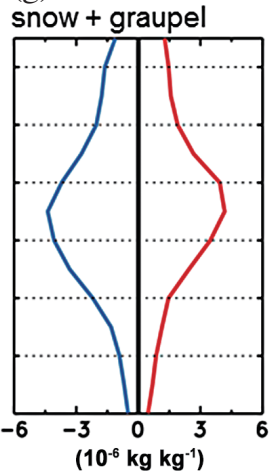

(d)

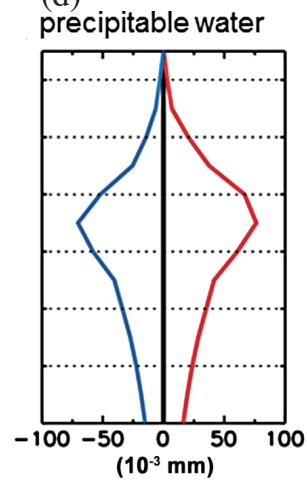

Fig. 9. Vertical profiles of the averaged anomalies in (a) air temperature, (b) pressure, (c) water vapor mixing ratio, (d) precipitable water, (e) wind speed, (f) cloud water and ice mixing ratio, and (g) snow and graupel mixing ratio for the WSST (red lines) and CSST (blue lines) cases over the Yellow Sea $\left(34.5^{\circ}-38.5^{\circ} \mathrm{N}, 122.5^{\circ}-126.5^{\circ} \mathrm{E}\right)$ in December 2012. 
for the WSST (CSST) case propagating in the upper levels up to $500 \mathrm{hPa}$ (Fig. 9b). The water vapor and precipitable water showed positive (negative) anomalies for the WSST (CSST) case due to the air heat capacity induced by the warm (cold) SST (Figs. 9c and d). The anomalies of wind speed were positive (negative) at the surface for the WSST (CSST) case. The same was true for the upper levels but at a relatively small magnitude. The anomalies for the cloud water and ice mixing ratio were negative (positive) at low levels (from the surface up to $950 \mathrm{hPa}$ ), reflecting the relatively warm (cold) air temperature, but were positive (negative) at mid-levels (from 950 - $700 \mathrm{hPa}$ ) for the WSST (CSST) case (Fig. 9f). The anomalies in the vertical structure of the snow and graupel mixing ratio were similar to those of precipitable water, with the peak anomalies occurring at maximum volumes of precipitable water.

Table 1 summarizes the statistics between the sensitivity model results and the surface observations at the $71 \mathrm{KMA}$ sites. As shown in Fig. 5, the CTL run tended to underestimate snowfall and surface pressure and slightly overestimate the surface temperature. The results from the CSST run were closer to the observations in relation to the other simulations. This analysis implies that the OSTIA SST data are relatively higher than the in situ measurements over the Yellow Sea, especially for coastal areas where satellite observations are prone to high errors (Fig. 1b), but that the effect of SST on snowfall formation is maximized. To validate this outcome, we also compared the OSTIA data with other in situ measurements from the Korea Oceanographic Data Center (KODC) (available at http://www.nfrdi.re.kr), which provides SST, salinity, oxygen, and phosphate concentrations for 175 stations around the Korean Peninsula. In general, in December 2012 the KODC data was higher than the OSTIA data for the Yellow Sea. However, for the coastal regions, the OSTIA SST was $0.5-1 \mathrm{~K}$ higher than the in situ measurements, especially for the area offshore the Chungcheong and Jeolla provinces (Fig. 10). This result is consistent with the decreased SST data in the CSST experiment showing an improved agreement with the observations at the KMA sites (Table 1). We found slightly larger discrepancies between the two datasets in the East/Japan Sea, which might affect meteorological systems. This issue will be subject to further research.

\section{CONCLUSIONS}

When the strong Siberian High, associated with a cold air mass, expands towards the Korean Peninsula, SST deviations play an important role in the air-sea interaction over the Yellow Sea. In this study, we examined the effect of SST errors on the meteorological fields in Korea using the satellite-based OSTIA SST data and the WRF model. The analysis was performed for December 2012 when a severe snowfall occurred in Korea.

First, the OSTIA SST data was compared with in situ buoy measurements from three sites in the Yellow Sea. The OSTIA SST generally reproduced well the in situ buoy SST with a low RMSE of $0.14-0.17 \mathrm{~K}$ for daily mean values. The baseline WRF simulation using the OSTIA SST data generally captured the spatial distribution of the observed snowfall, surface air temperature, and surface pressure in the Korean Peninsula, but underestimated the snowfall in the southern coastal areas. Despite this discrepancy, the model generally captured the spatial and temporal variabilities with high $\mathrm{R}$ values for snowfall $(\mathrm{R}=0.86)$ in Korea.

We then examined the effect of the OSTIA SST errors of $1.5-2 \mathrm{~K}$ in the coastal sea on the meteorological fields for the Korean Peninsula by conducting two sensitivity simulations using increased (WSST) and decreased (CSST) OSTIA SST values according to the OSTIA SST errors. The sensitivity simulations showed that the atmospheric variables were largely influenced by SST perturbations. Comparing with the baseline simulation over the Yellow Sea in December 2012, the atmospheric variables showed a variation of $+0.8 /-0.7 \mathrm{~K}$ for surface air temperature, $+38 /-34 \mathrm{~W} \mathrm{~m}^{-2}$ for heat flux, $\pm 0.6 \mathrm{hPa}$ for surface pressure, $\pm 0.3 \mathrm{~m} \mathrm{~s}^{-1}$ for

Table 1. Statistics of the simulated snowfall (in $\mathrm{cm}$ ), surface air temperature (in K), and surface pressure (in hPa) in December 2012 for the WSST and CSST cases, including correlation coefficients $(R)$ and mean bias $(M B=\bar{M}-\bar{O}$, where $M$ and $O$ are the modeled and observed values, respectively) between the model and observations sampled at $71 \mathrm{KMA}$ sites.

\begin{tabular}{c|cc|cc|cc}
\hline \multirow{2}{*}{ EXP } & \multicolumn{2}{|c|}{ Snowfall } & \multicolumn{2}{c|}{$\begin{array}{c}\text { Surface air } \\
\text { temperature }\end{array}$} & \multicolumn{2}{c}{ Surface pressure } \\
\cline { 2 - 7 } & $\mathbf{R}$ & MB & R & MB & R & MB \\
\hline WSST & 0.58 & -15.4 & 0.96 & 1.5 & 0.92 & -6.3 \\
CSST & 0.75 & -10.8 & 0.97 & 0.2 & 0.92 & -5.1 \\
\hline
\end{tabular}

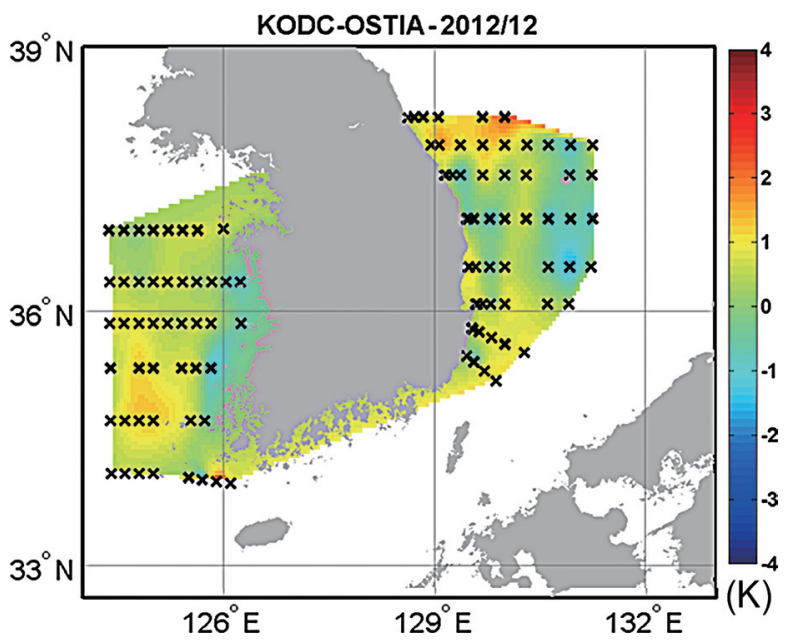

Fig. 10. Difference between the Korea Oceanographic Data Center (KODC) and OSTIA SST (in K) around the Korean Peninsula in December 2012 
surface wind speed, and $+12.2 /-11.8 \mathrm{~mm}$ for accumulated precipitation for the WSST and CSST cases, respectively. The changes in surface air temperature were positively correlated with the SST errors with $0.62 / 0.60 \mathrm{~K} \mathrm{~K}^{-1}$, whereas changes in the surface pressure were negatively correlated with $-0.47 /-0.43 \mathrm{hPa} \mathrm{K}^{-1}$. The precipitation volume was directly controlled by the SST errors with changes in $\pm 9 \%$ for snowfall and $\pm 18 \%$ for rainfall relatively to the baseline simulation for the Yellow Sea.

Changes in the SST data resulted in changes in the upper layer meteorological fields by a symmetrical structure with respect to warm and cold SSTs. The anomalies in air temperature, pressure, wind speed and hydrometeors due to SST perturbations propagated to the upper part of the cloud top levels up to $700 \mathrm{hPa}$. However, the ice mixing ratio showed a nonlinear combination for the results at low and mid-levels.

In this study, we demonstrated the effect of SST errors on the meteorological fields in Korea. However, numerical experiments for the entire winter season were not performed, so a different SST effect may occur in February and early March. During the experimental period, the effect of SST deviations on the wind fields was relatively weak due to a strong northwesterly wind from the continent. Therefore, further work is necessary to examine the SST effect on the wind fields, especially for the coastal region during the periods of weak synoptic wind.

Acknowledgements This work was supported by the Korea Meteorological Administration Research and Development Program under Grant CATER 2012-2081.

\section{REFERENCES}

Cha, Y. M., H. W. Lee, and S. H. Lee, 2011: Impacts of the high-resolution sea surface temperature distribution on modeled snowfall formation over the Yellow Sea during a cold-air outbreak. Weather Forecast., 26, 487503, doi: 10.1175/WAF-D-10-05019.1. [Link]

Chen, F. and J. Dudhia, 2001: Coupling an advanced land surface-hydrology model with the Penn State-NCAR MM5 Modeling system. Part II: Preliminary model validation. Mon. Weather Rev., 129, 587-604, doi: 10.1 175/1520-0493(2001)129<0587:CAALSH>2.0.CO;2. [Link]

Cheong, S. H., K. Y. Byun, and T. Y. Lee, 2006: Classification of snowfalls over the Korean peninsula based on developing mechanism. Atmosphere, 16, 33-48. (in Korean)

Cronin, M. F., S. P. Xie, and H. Hashizume, 2003: Barometric pressure variations associated with eastern Pacific tropical instability waves. J. Climate, 16, 3050-3057, doi: 10.1175/1520-0442(2003)016<3050:BPVAWE $>2$. 0.CO;2. [Link]

Dash, P., A. Ignatov, M. Martin, C. Donlon, B. Brasnett,
R. W. Reynolds, V. Banzon, H. Beggs, J. F. Cayula, Y. Chao, R. Grumbine, E. Maturi, A. Harris, J. Mittaz, J. Sapper, T. M. Chin, J. Vazquez-Cuervo, E. M. Armstrong, C. Gentemann, J. Cummings, J. F. Piollé, E. Autret, J. Roberts-Jones, S. Ishizaki, J. L. Høyer, and D. Poulter, 2012: Group for High Resolution Sea Surface Temperature (GHRSST) analysis fields inter-comparisons-Part 2: Near real time web-based level 4 SST Quality Monitor (L4-SQUAM). Deep-Sea Res. Part II-Top. Stud. Oceanogr., 77-80, 31-43, doi: 10.1016/j.dsr2.2012.04.002. [Link]

Donlon, C. J., M. Martin, J. Stark, J. Roberts-Jones, E. Fiedler, and W. Wimmer, 2012: The Operational Sea Surface Temperature and Sea Ice Analysis (OSTIA) system. Remote Sens. Environ., 116, 140-158, doi: 10.1016/j.rse.2010.10.017. [Link]

Dudhia, J., 1989: Numerical study of convection observed during the winter monsoon experiment using a mesoscale two-dimensional model. J. Atmos. Sci., 46, 3077-3107, doi: 10.1175/1520-0469(1989)046<3077: NSOCOD $>2.0 . C O ; 2$. [Link]

Hong, S. Y. and J. Dudhia, 2012: Next-generation numerical weather prediction: Bridging parameterization, explicit clouds, and large eddies. Bull. Amer. Meteorol. Soc., 93, ES6-ES9, doi: 10.1175/2011BAMS3224.1. [Link]

Hong, S. Y., Y. Noh, and J. Dudhia, 2006: A new vertical diffusion package with an explicit treatment of entrainment processes. Mon. Weather Rev., 134, 2318-2341, doi: 10.1175/MWR3199.1. [Link]

Jeong, J. and R. Park, 2013: A study of the effects of SST deviations on heavy snowfall over the Yellow Sea. Atmosphere, 23, 161-169, doi: 10.14191/ Atmos.2013.23.2.161. (in Korean) [Link]

Kain, J. S., 2004: The Kain-Fritsch convective parameterization: An update. J. Appl. Meteorol., 43, 170-181, doi: 10.1175/1520-0450(2004)043<0170:TKCPAU>2. 0.CO;2. [Link]

Kang, S. D. and J. B. Ahn, 2008: Numerical study on the formation and maintenance mechanisms of cloud street in the East Sea during cold air outbreak. Asia-Pac. J. Atmos. Sci., 44, 105-119.

Lee, Y. H., 2002: Numerical simulation of structure and property of cloud street over East Sea. Atmosphere, 12, 326-328. (in Korean)

Lim, K. S. S. and S. Y. Hong, 2010: Development of an effective double-moment cloud microphysics scheme with prognostic cloud condensation nuclei $(\mathrm{CCN})$ for weather and climate models. Mon. Weather Rev., 138, 1587-1612, doi: 10.1175/2009MWR2968.1. [Link]

Martin, M., P. Dash, A. Ignatov, V. Banzon, H. Beggs, B. Brasnett, J. F. Cayula, J. Cummings, C. Donlon, C. Gentemann, R. Grumbine, S. Ishizaki, E. Maturi, R. W. Reynolds, and J. Roberts-Jones, 2012: Group for High Resolution Sea Surface temperature (GHRSST) 
analysis fields inter-comparisons. Part 1: A GHRSST multi-product ensemble (GMPE). Deep-Sea Res. Part II-Top. Stud. Oceanogr., 77-80, 21-30, doi: 10.1016/j. dsr2.2012.04.013. [Link]

Mlawer, E. J., S. J. Taubman, P. D. Brown, M. J. Iacono, and S. A. Clough, 1997: Radiative transfer for inhomogeneous atmospheres: RRTM, a validated correlated-k model for the longwave. J. Geophys. Res., 102, 1666316682, doi: 10.1029/97JD00237. [Link]

Moeng, C. H., J. Dudhia, J. Klemp, and P. Sullivan, 2007: Examining two-way grid nesting for large eddy simulation of the PBL using the WRF model. Mon. Weather Rev., 135, 2295-2311, doi: 10.1175/MWR3406.1. [Link]

O'Neill, L. W., D. B. Chelton, and S. K. Esbensen, 2012: Covariability of surface wind and stress responses to sea surface temperature fronts. J. Climate, 25, 59165942, doi: 10.1175/JCLI-D-11-00230.1. [Link]

Park, K. A., F. Sakaida, and H. Kawamura, 2008: Error characteristics of satellite-observed sea surface temperatures in the Northeast Asian sea. J. Korean Earth Sci. Soc., 29, 280-289, doi: 10.5467/JKESS .2008.29.3.280. (in Korean) [Link]

Park, R. S., Y. K. Cho, B. J. Choi, and C. H. Song, 2011: Implications of sea surface temperature deviations in the prediction of wind and precipitable water over the Yellow Sea. J. Geophys. Res., 116, D17106, doi: 10.1029/2011JD016191. [Link]
Reynolds, R. W., T. M. Smith, C. Liu, D. B. Chelton, K. S. Casey, and M. G. Schlax, 2007: Daily high-resolutionblended analyses for sea surface temperature. J. Climate, 20, 5473-5496, doi: 10.1175/2007JCLI1824.1. [Link]

Ryoo, S. B., W. T. Kwon, and J. G. Jhun, 2004: Characteristics of wintertime daily and extreme minimum temperature over South Korea. Int. J. Climatol., 24, 145-160, doi: 10.1002/joc.990. [Link]

Skamarock, W. C., J. B. Klemp, J. Dudhia, D. O. Gill, D. M. Barker, W. Wang, and J. G. Powers, 2005: A description of the advanced research WRF version 2. National Center for Atmospheric Research, NCAR Technical Note, NCAR/TN-468 STR, Colorado, USA, 88 pp.

Small, R. J., S.P.Xie, and Y. Wang, 2003: Numerical simulation of atmospheric response to Pacific tropical instability waves.J.Climate, 16,3723-3741, doi: 10.1175/15200442(2003)016<3723:NSOART>2.0.CO;2. [Link]

Stark, J. D., C. J. Donlon, M. J. Martin, and M. E. McCulloch, 2007: OSTIA: An operational, high resolution, real time, global sea surface temperature analysis system. OCEANS 2007 - Europe, IEEE Press, Piscataway, New Jersey, USA, 1-4, doi: 10.1109/ OCEANSE.2007.4302251. [Link]

Xie, J., J. Zhu, and Y. Li, 2008: Assessment and intercomparison of five high-resolution sea surface temperature products in the shelf and coastal seas around China. Cont. Shelf Res., 28, 1286-1293, doi: 10.1016/j. csr.2008.02.020. [Link] 